\title{
Antibiotics and probiotics in inflammatory bowel disease: when to use them?
}

\author{
Bincy Abraham (1) , Eamonn M M Quigley
}

Gastroenterology and Hepatology, Houston Methodist, Houston, Texas, USA

\section{Correspondence to} Dr Bincy Abraham,

Gastroenterology \& Hepatology, Houston Methodist, Houston, TX 77030, USA; bpabraham@ houstonmethodist.org

Received 18 December 2018 Revised 26 February 2019 Accepted 5 March 2019 Published Online First 22 March 2019

\section{Check for updates}

(C) Author(s) (or their employer(s)) 2020. No commercial re-use. See rights and permissions. Published by BMJ.

To cite: Abraham $B$, Quigley EMM. Frontline Gastroenterology

2020;11:62-69.

\section{ABSTRACT}

Antibiotics and probiotics are often used as adjunctive therapy in inflammatory bowel disease. However, data are limited and randomised controlled trials are too inconsistent to provide generalised recommendations for their use in all patients with ulcerative colitis or Crohn's disease. Antibiotics are best used in the management of infectious complications and fistulas in Crohn's disease and, perhaps, in reducing the intensity of inflammation in luminal disease. Ciprofloxacin, metronidazole and rifaximin have been most widely used and studied. On the other hand, there appears to be a limited role for antibiotics in ulcerative colitis (UC). Probiotics are most effective in pouchitis, and may have a role in the initial therapy and maintenance of remission in mild UC; the probiotic cocktail VSL\#3 has been the most widely studied. There is scant evidence of efficacy for probiotics in Crohn's disease.

Therapies which are now known to impact on the microbiota have been used for decades, largely on an empirical basis, in the management of inflammatory bowel disease (IBD). Antibiotics were used primarily in the prevention and management of infectious complications and probiotics for presumed overall benefits on gut health. A scientific basis for the use of microbiota-directed strategies in IBD came with the recognition that the gut microbiota and the host immune response to its luminal bacterial populations appeared to be fundamental to the pathogenesis of both Crohn's disease (CD) and ulcerative colitis (UC). This has, in turn, re-energised interest in microbial therapeutics in IBD.

\section{ANTIBIOTICS}

In theory, antibiotics could benefit patients with IBD by reducing the load

\section{Key messages}

- In Crohn's disease, rifaximin and ciprofloxacin may have some benefit in induction of remission, while antimycobacterial therapies may reduce the risk of relapse in quiescent disease.

- The combination of metronidazole and ciprofloxacin can help treat perianal fistulae but, if used as the sole form of therapy, recurrence inevitably occurs once discontinued.

- Short-term use of rifaximin or nitroimidazole antibiotics may help reduce the risk of postoperative recurrence of Crohn's disease.

- In ulcerative colitis (UC), combinations of antibiotics yielded the best results in active disease with limited data on maintenance of remission; however, antibiotic side effects and bacterial resistance precludes their long-term use.

- Antibiotics are effective in acute pouchitis but less effective in chronic refractory pouchitis.

- The strongest data to support the use of probiotics are in pouchitis and, particularly, for VSL\#3, in both the primary prevention of pouchitis after ileal pouch anal anastomosis and maintenance of remission following successful antibiotic treatment of acute pouchitis.

- There are some but inconsistent data to support the use of probiotics in UC with the strongest evidence for their efficacy in mild disease. There is little evidence of effectiveness of probiotics in Crohn's disease.

- Most studies of probiotics shared many limitations, including wide variability in the composition, viability and dosing of the probiotic preparation, employed, small sizes of the study population as well as a failure to confounding factors such as concomitant medications and diet. 
Table 1 Randomised controlled trials of antibiotics of potential efficacy in Crohn's disease, ulcerative colitis and pouchitis

\begin{tabular}{|c|c|c|c|}
\hline Indication & Endpoint (outcome) & Antibiotic & References \\
\hline \multirow[t]{4}{*}{ Crohn's disease } & Induction of remission & $\begin{array}{l}\text { Rifaximin } 800 \text { mg twice daily (NNT 9, clinical remission) } \\
\text { Ciprofloxacin } 500 \text { mg twice daily (NNT 4, clinical remission of colonic } \\
\text { disease) } \\
\text { Metronidazole (reduction of CRP) }\end{array}$ & 10111316 \\
\hline & Maintenance of remission & Anti-Mycobacterium avium paratuberculosis therapy (NNT 4) & 182022 \\
\hline & Perianal disease & Metronidazole+ciprofloxacin (NNT 5) & 29 \\
\hline & $\begin{array}{l}\text { Prevention of postoperative } \\
\text { recurrence }\end{array}$ & $\begin{array}{l}\text { Metronidazole } 20 \mathrm{mg} / \mathrm{kg} / \text { day } \times 3 \text { months (NNT 4) } \\
\text { Ornidazole } \times 1 \text { year (NNT 4) } \\
\text { Rifaximin } \times 3 \text { months ( } 10 \% \text { vs } 40 \% \text { placebo recurrence) }\end{array}$ & 313234 \\
\hline \multirow[t]{2}{*}{ Ulcerative colitis } & Induction of remission & $\begin{array}{l}\text { Metronidazole+tobramycin } \\
\text { Metronidazole+amoxicillin+tetracycline } \\
\text { Metronidazole+tobramycin+vancomycin/rifaximin } \\
\text { *(For } 7 \text { days to } 3 \text { months) }\end{array}$ & 54347 \\
\hline & Maintenance of remission & No evidence of efficacy of antibiotics & \\
\hline \multirow[t]{2}{*}{ Pouchitis } & Acute pouchitis & $\begin{array}{l}\text { Metronidazole } 1 \text { to } 1.5 \mathrm{~g} / \text { day } \\
\text { Ciprofloxacin } 500 \mathrm{mg} \text { twice daily+metronidazole } 20 \mathrm{mg} / \mathrm{kg} / \text { day } \times 2 \text { weeks }\end{array}$ & 5051 \\
\hline & Maintenance of remission & Rifaximin up to $1800 \mathrm{mg} /$ day (benefit up to 12 months only) & 54 \\
\hline
\end{tabular}

CRP, C reactive protein; NNT, number needed to treat.

of gut-derived bacterial toxins and antigenic triggers. When considering the use of antibiotics in IBD, one must always balance any benefits derived from their use against risks. Given the natural history of IBD, such use is likely to be long term thus exposing the patient to side effects as well as their impact on commensal bacteria. The latter may, indeed, result in the further disruption of the microbiota with a reduction in overall diversity, the development of a niche for the growth of Clostridium difficile and the outgrowth of fungal species. ${ }^{1}$ The emergence of resistance is another potential hazard, with long-term antibiotic use being associated with the emergence of such important bacteria as methicillin-resistant Staphylococcus aureus (MRSA) and vancomycin-resistant Enterococci (VRE), taxa that occur more commonly among patients with IBD. ${ }^{2}$ Also, antibiotics may affect metabolism of bile acids, cholesterol and vitamins. ${ }^{4}$ Long-term data on antibiotic effects on the microbiome, especially in patients with IBD, are lacking. See table 1 for a summary of all randomised controlled trials (RCTs) of antibiotics with potential efficacy in IBD.

\section{Crohn's disease}

Induction of remission

In a systematic review and meta-analysis on the induction of remission in CD, 10 RCTs including over 1000 patients were assessed. ${ }^{5}$ Unfortunately, due to the use of different antibiotics tested as well as the prevalence of co-therapy with other medications, no generalisable conclusions on the use of antibiotics in CD could be made. Primary outcomes were, for the most part, limited to clinical indices rather than endoscopic or other objective measures. Consequently, the clinical improvements observed could have resulted not on the basis of a reduction in inflammation but from impacts on coexistent irritable bowel syndrome or small intestinal bacterial overgrowth. ${ }^{6}$

Rifaximin is a non-absorbable antibiotic virtually devoid of systemic side effects. ${ }^{7}$ Rifaximin holds particular promise in CD by virtue of demonstrated effects on the colonic microbiome which feature a bloom of potentially beneficial bacteria such as Bifidobacteria and Faecalibacterium prausnitzii. ${ }^{8}$ It may also exert anti-inflammatory effects by antagonising the effects of tumour necrosis factor- $\alpha$ on intestinal epithelial cells. ${ }^{9}$ Rifaximin tested against placebo was found to be effective at inducing remission in active Crohn's based on two RCTs of 485 patients with a number needed to treat (NNT) of $9 .{ }^{10} 11$ In one study, remission rates, defined as Colitis Disease Activity Index $(\mathrm{CDAI})<150$, achieved significance only among with baseline elevation of $\mathrm{C}$ reactive protein (CRP). ${ }^{10}$ In a larger international RCT, a dose of $800 \mathrm{mg}$ twice daily was found to be most effective in inducing clinical remission. ${ }^{11}$

In an RCT of 84 patients with CD, ciprofloxacin was found to be effective with a NNT of $4 .{ }^{12}$ However, when combined with budesonide and metronidazole, there was no significant impact on inducing remission in active $\mathrm{CD}$, though some efficacy was found in colonic disease in comparison with isolated small bowel disease. ${ }^{13}$ Other studies of metronidazole in combination with other antibiotics, such as cotrimoxazole or with ciprofloxacin, did not show efficacy. ${ }^{14}{ }^{15}$ However, in one study of metronidazole alone, a significant reduction in CRP $(0.8 \mathrm{mg} / \mathrm{dL}$ vs $-0.9 \mathrm{mg} / \mathrm{dL} ; \mathrm{p}<0.05)$ was achieved in comparison placebo. ${ }^{16}$ An earlier study suggested that metronidazole was as effective as sulfasalazine ${ }^{17}$; an observation of questionable clinical significance given minimal efficacy of 5-ASA in CD. Metronidazole has numerous 
side effects including nausea, dyspepsia, dysgeusia, anorexia and, of greater concern, neuropathy that limit its short-term tolerance and long-term use. Other antibiotics including clarithromycin and clofazamine did not show any benefit in active CD.

The long-touted proposal that Mycobacterium avium paratuberculosis (MAP) might cause CD provided the rationale for antituberculous therapy in CD. However, few RCTs evaluated this and overall combined data suggested no benefit. Whether evaluating clinical, endoscopic or secondary endpoint (such as intestinal permeability), initial small studies provided little encouragement for this strategy. ${ }^{18} 19$ A larger trial of 213 patients, while enhancing remission rates at 16 weeks, failed to sustain this advantage at 3 years and, in secondary analyses, there was no improvement in Crohn's disease index of severity (CDEIS) scores or the inflammatory markers CRP or erythrocyte sedimentation rate. ${ }^{20}$

\section{Maintenance of remission}

A study that evaluated recent antibiotics prescription use among 1205 patients showed that antibiotic use reduced the risk of CD flare in the following 60 days. ${ }^{21}$ Three RCTs evaluated the use of antibiotics (anti-MAP therapy) to prevent relapse in quiescent CD and showed efficacy, in comparison with placebo, in preventing relapse in CD for up to 9 to 12 months and with a NNT of $4 .{ }^{18} 2022$ However, this was achieved only in the context of an induction. Quite apart from the inconclusive nature of these, a high rate of side effects and the potential for the development of antibiotic resistance may limit the use of this approach in the maintenance of remission in $\mathrm{CD} .^{23}$

Uncontrolled studies in perianal disease showed that metronidazole in a dose of $20 \mathrm{mg} / \mathrm{kg}$ can close $62 \%-83 \%$ of fistulae 24 and the combination of metronidazole and ciprofloxacin improved symptoms in $64 \%$ and closed fistulae in $21 \% .{ }^{26}$ Three randomised trials evaluated the use of antibiotics given over 4 to 12 weeks in 125 patients with $C D$ with perianal fistulas. Although the two individual antibiotic trials of ciprofloxacin versus placebo, ${ }^{27}$ or metronidazole versus placebo, ${ }^{28}$ did not show any benefit with either antibiotic, the combination was effective $(\mathrm{NNT}=5){ }^{29}$ Antibiotics may reduce fistula drainage, but may not always provide complete healing, ${ }^{30}$ and fistulae tend to recur in most patients following cessation of therapy. Thus, antibiotics should be used in conjunction with other definitive $\mathrm{CD}$ treatments rather than alone.

\section{Prevention of postoperative $\mathrm{CD}$ recurrence}

Perhaps the most intriguing concept is the use of antibiotics to reduce the risk of postoperative recurrence. Among the various RCTs, nitroimidazole antibiotics (metronidazole $20 \mathrm{mg} / \mathrm{kg} /$ day for 3 months, ornidazole use for 1 year) successfully prevented clinical and endoscopic recurrence $(\mathrm{NNT}=4) .{ }^{31}{ }^{32}$ However, long-term use may be hindered by a high rate of adverse events leading to patient withdrawal. ${ }^{33}$

Rifaximin given for 3 months also reduced the rate of endoscopic recurrence ( $10 \%$ vs $40 \%$ for placebo). ${ }^{34}$ Ciprofloxacin did not achieve statistical significance but did show a trend towards reduced postoperative recurrence. ${ }^{35}$ An uncontrolled trial showed no benefit of anti-MAP therapy with rifabutin and ethambutol in preventing postoperative recurrence of $\mathrm{CD} .^{36}$

\section{Ulcerative colitis}

Induction of remission

Meta-analyses of several RCTs including over 5000 patients showed higher overall remission rates with antibiotics in the management of active UC $(\mathrm{NNT}=7) .{ }^{537}$ For the most part, studies of individual antibiotics such as ciprofloxacin ${ }^{38-41}$ or vancomycin ${ }^{42}$ did not demonstrate efficacy. When seen, short-term benefits did not translate into longer-term remission. ${ }^{41}$

In contrast, studies of antibiotic combinations (metronidazole, tobramycin), (metronidazole, amoxicillin, tetracycline) or (metronidazole, tobramycin, vancomycin or rifaximin) given for 7 days to 3 months in moderate UC did show benefit. ${ }^{5}$ Not surprisingly, oral administration generated favourable responses compared with intravenous administration. ${ }^{43}$ For example, oral tobramycin improved remission rates within 1 week in acute UC (74\% vs $43 \%$ for placebo).$^{44}$ In two studies that evaluated the combination of amoxicillin, tetracycline and metronidazole in active UC, both clinical response and remission rates as well as endoscopic remission were enhanced for up to 1 year. $^{45} 46$

The addition of rifaximin $400 \mathrm{mg}$ twice daily to a group of patients with moderate to severe UC refractory to steroid therapy improved stool frequency and sigmoidoscopic appearances and reduced rectal bleeding. ${ }^{47}$ The use of repeated rifaximin dosing in this population should be weighed against the observation that resistant Bifidobacterium sp. were seen to emerge after three intermittent courses among patients with $\mathrm{UC}^{48}$

\section{Maintenance of remission}

Only one RCT evaluated the short-term (7 days) use of an antibiotic (tobramycin) to maintain remission of quiescent patients with UC-relapse rates were similar to placebo at 1 and 2 years. ${ }^{49}$

\section{Pouchitis}

Bacterial overgrowth and faecal stasis in the small intestinal pouch fashioned following total colectomy with ileal pouch anal anastomosis may contribute to the development of pouchitis. Thus, most patients with pouchitis are treated with antibiotics.

Metronidazole, in a dose of 1 to $1.5 \mathrm{~g} /$ day, induces a rapid response in acute pouchitis. ${ }^{50}$ In a small RCT, both ciprofloxacin (500 mg twice daily) and 
metronidazole $(20 \mathrm{mg} / \mathrm{kg} /$ day $)$ for 2 weeks were efficacious in treating acute pouchitis. ${ }^{51}$

Although these studies show that both antibiotics are successful in the treatment of acute pouchitis, ciprofloxacin has the edge: it leads to a greater reduction in total Pouchitis Disease Activity Index scores and endoscopic scores, is associated with more symptom improvement and has better tolerability than metronidazole. ${ }^{51}$

\section{Chronic pouchitis}

Chronic or refractory pouchitis provides a greater therapeutic challenge. Data are limited. In an open-label study, rifaximin $1000 \mathrm{mg}$ twice daily in combination with ciprofloxacin $500 \mathrm{mg}$ twice daily was given for 15 days to 18 patients with pouchitis that had failed to respond to metronidazole or ciprofloxacin alone. Moreover, 55\% demonstrated a clinical response and $33 \%$ achieved clinical remission. ${ }^{52}$ Even greater efficacy (82\% remission rate) was achieved in another open-label trial involving metronidazole $(800 \mathrm{mg}$ to $1 \mathrm{~g}$ daily) and ciprofloxacin ( $1 \mathrm{~g}$ daily) for 28 days. ${ }^{53}$

Rifaximin, in doses up to $1800 \mathrm{mg} / \mathrm{day}$, was assessed as maintenance therapy in patients with antibioticdependent pouchitis; at 3 months, $65 \%$ had achieved remission and $79 \%$ of these remained in remission at 6 months and $58 \%$ at 12 months. However, this rate plummeted to only $6 \%$ at 24 months. ${ }^{54}$

In a small cross-over RCT, metronidazole $400 \mathrm{mg}$ oral three times a day for 2 weeks improved stool frequency but was no better than placebo in inducing endoscopic or histological improvement. ${ }^{55}$ Not surprisingly, over half the patients (55\%) reported side effects of nausea, vomiting, abdominal discomfort, headache, skin rash and metallic taste.

\section{PROBIOTICS}

Patients with IBD are attracted to probiotics as a readily available 'natural' treatment option. It is thus important to discuss their use in patients with IBD and understand their role based on the available evidence.

Probiotics are live micro-organisms that when administered in sufficient amounts alter the microflora and provide a health benefit to the host. ${ }^{56-58}$ Probiotics may help in reducing inflammation in IBD by modulating the composition of the microbiota through inhibition of pathogenic enteric bacteria, improving and restoring epithelial and mucosal barrier function and promoting an anti-inflammatory milieu. ${ }^{59-61}$

However, probiotic preparations vary significantly in composition, dosage and interaction with the host, and these must be considered before recommending their use. Also, in order to exert their optimal effect, probiotics must survive their journey through the upper gastrointestinal tract by remaining viable after contact with stomach acid, bile and digestive enzymes-a fundamental property that is not tested in relation to many products. Furthermore, many probiotics on
Table 2 Randomised controlled trials of probiotics with efficacy in Crohn's disease, ulcerative colitis and pouchitis

\begin{tabular}{|c|c|c|c|}
\hline Indication & $\begin{array}{l}\text { Endpoint } \\
\text { (outcome) }\end{array}$ & Probiotic & References \\
\hline $\begin{array}{l}\text { Crohn's } \\
\text { disease }\end{array}$ & $\begin{array}{l}\text { Induction/ } \\
\text { maintenance of } \\
\text { remission }\end{array}$ & Done & \\
\hline \multirow[t]{2}{*}{$\begin{array}{l}\text { Ulcerative } \\
\text { colitis }\end{array}$} & $\begin{array}{l}\text { Induction of } \\
\text { remission }\end{array}$ & $\begin{array}{l}\text { VSL\#3 (children) } \\
\text { Bifidobacterium } \\
\text { and Lactobacillus } \\
\text { acidophilus } \\
\text { Lactobacillus } \\
\text { reuteri enema } \\
\text { (children) }\end{array}$ & 767779 \\
\hline & $\begin{array}{l}\text { Maintenance of } \\
\text { remission }\end{array}$ & $\begin{aligned} \text { Difidobacterium } \\
\text { breve } \\
\text { Bifidobacterium } \\
\text { bifidum } \\
\text { Saccharomyces } \\
\text { boulardii } \\
\text { - E. coli Nissle } \\
1917 \\
\text { VSL\#3 (children) }\end{aligned}$ & $7681-83$ \\
\hline \multirow[t]{2}{*}{ Pouchitis } & Acute pouchitis & VSL\#3 & 89 \\
\hline & $\begin{array}{l}\text { Maintenance of } \\
\text { remission }\end{array}$ & VSL\#3 & 9293 \\
\hline
\end{tabular}

the market have not been clinically evaluated for their claims of efficacy in IBD. Though well tolerated and generally safe, there is a theoretical concern relating to their use in immunosuppressed patients with an altered mucosal barrier. ${ }^{62}{ }^{63}$ Since probiotic strains typically do not colonise the adult colon and repeated or indefinite use is required for an ongoing effect, long-term maintenance studies in IBD are needed. ${ }^{59}$ See table 2 for a summary of RCTs of probiotics with efficacy in IBD.

\section{Crohn's disease}

Induction of remission

Data on the induction of remission with probiotics in Crohn's disease are very limited. Two open-label studies included a total of only 14 patients and, while showing an improvement in CDAI, used different preparations, Lactobacillus rhamnosus GG in one study and a combination of Lactobacillus and Bifidobacterium in the other. ${ }^{6465}$ In the only RCT, where 11 patients were randomised to placebo or Lactobacillus GG following 1 week of treatment with both antibiotics and steroids, no benefits were evident for the probiotic, with only five patients completing the study. ${ }^{66}$

\section{Maintenance of remission}

Lactobacillus rhamnosus GG treatment in children showed no benefit compared with placebo and was terminated early due to lack of efficacy and difficulty in recruitment. ${ }^{67}$ In a randomised trial of 165 patients with CD who achieved remission on steroids or salicylates, Saccharomyces boulardii did not reduce recurrence rates after 52 weeks. ${ }^{68}$ Similarly, Lactobacillus 
johnsonii and Escherichia coli Nissle 1917 also failed to show any impact on remission rates in other studies. ${ }^{69-71}$

\section{Prevention of postoperative recurrence}

In a large study evaluating postoperative recurrence, VSL\#3 (a combination of Streptococcus thermophilus, Bifidobacterium breve, Bifidobacterium longum, Bifidobacterium infantis, Lactobacillus acidophilus, Lactobacillus plantarum, Lactobacillus paracasei and Lactobacillus delbrueckii subsp. bulgaricus) was ineffective in reducing the endoscopic relapse rate at 90 days. ${ }^{72}$ However, a lower rate of recurrence and lower levels of mucosal inflammatory cytokines among patients who received VSL\#3 for 1 year suggested some efficacy with longer use.

\section{Ulcerative colitis}

Induction of remission

A Cochrane systematic review (involving 244 patients) of $S$. boulardii and VSL\#3 in mild to moderate UC in combination with conventional therapy failed to demonstrate an improvement in remission rates, but provided a modest benefit in terms of reducing disease activity. ${ }^{73}$ Another study found no difference between VSL\#3 and placebo based on endoscopic scores and physician's global assessment. ${ }^{74}$

Studies evaluating the use of VSL\#3 with other standard of care medical therapy for UC looked more promising. The addition of VSL\#3 to standard therapy with aminosalicylates or thiopurines was found to increase remission rates (reduction in Ulcerative Colitis Disease Activity Index [UCDAI] score by more than 50\%) and mucosal healing (subscore of 0 or 1 in sigmoidoscopy activity) at 12 weeks. ${ }^{75}$ Unfortunately, this study was limited by its short duration and a high dropout rate in the placebo group. An RCT of 29 children with newly diagnosed UC followed for 1 year found that VSL\#3 in addition to steroids and 5-ASA resulted in a remission rate of $93 \%$ compared with just $36 \%$ in those treated with standard therapy plus placebo. ${ }^{76}$

Treatment with a bifidobacteria-fermented milk containing Bifidobacterium strains and Lactobacillus acidophilus in a Japanese RCT in mild to moderate UC showed a significant reduction in endoscopic and histological scores compared with placebo. ${ }^{77}$ Conversely, a Danish cross-over study of 100 patients with UC with active disease randomised to ciprofloxacin or placebo for 1 week followed by E. coli Nissle versus placebo for 7 weeks found that fewer patients on the probiotic achieved clinical remission. ${ }^{40}$ In addition, the probiotic group had the largest number of withdrawals from the trial suggesting that certain bacterial strains may even be detrimental for use in patients with IBD.

The same probiotic, E. coli Nissle 1917, administered rectally for proctitis or proctosigmoiditis, did not show benefit compared with placebo. $^{78}$ On the other hand, an enema combining Lactobacillus reuteri ATCC 55730 and mesalamine was more effective than mesalamine alone in 40 children with mild to moderate ulcerative proctitis or ulcerative rectosigmoiditis; $100 \%$ in the probiotic group had a clinical response (Mayo Disease Activity Index [MDAI] reduction of $\geq 2$ ) and $31 \%$ reached remission (MDAI score of $<2.0$ ), compared with rates of $53 \%$ and $0 \%$ in the placebo group. ${ }^{79}$ However, only 31 children completed the study due to lack of compliance with rectal enema administration, and the follow-up lasted for only 8 weeks.

Maintenance of remission

RCTs involving E. coli Nissle 1917, S. boulardii, B. breve and B. bifidum strains Yakult have shown similar efficacy and safety to standard 5-ASA regimens in the maintenance of remission for patients with mild to moderate UC ${ }^{80}$ Three RCTs using E. coli Nissle 1917 found the probiotic to be as effective as low-dose mesalamine in maintaining remission based on histology, endoscopy or quality of life..$^{81-83}$ Conversely, an open-label RCT comparing Lactobacillus GG alone, mesalamine and the combination of Lactobacillus GG and mesalamine failed to show any difference in relapse or adverse event rates between the three groups over a 12-month period based on UCDAI scores. ${ }^{84}$ In children, some small studies have shown VSL\#3 to be effective in maintenance of remission. The addition of VSL\#3 to standard therapy decreased relapse rates $(21.4 \%$ vs $73.3 \%)$ compared with placebo. ${ }^{76}$ An open-label study of 18 children with UC reported improvement in endoscopic scores and inflammatory markers, with a clinical remission rate of $56 \%$ after 8 weeks of VSL\#3 in addition to standard treatment. ${ }^{85}$ Limitations of this study included a lack of a placebo, small study size, short duration of follow-up and high withdrawal rate.

In a small pilot study, six patients with UC in remission following a course of oral steroids were given a combination of rifaximin $400 \mathrm{mg}$ and the probiotic S. boulardii $500 \mathrm{mg}$ as a maintenance treatment for 3 month; all patients remained in clinical remission suggesting that this therapeutic combination can be useful in preventing early relapses of UC. ${ }^{86}$

\section{Pouchitis}

Pouchitis, or inflammation within the ileal reservoir, may occur in up to $60 \%$ of patients with UC following an ileal pouch anal anastomosis (IPAA) in patients with UC. ${ }^{87}$ Pouchitis can lead to symptoms of urgency, increased frequency of bowel movements and abdominal pain.

A small study in patients with acute pouchitis showed that although Lactobacillus GG altered the pouch flora, there was no clinical or endoscopic improvement compared with placebo. ${ }^{88}$ However, a study of 40 patients randomised to VSL\#3 or placebo immediately after IPAA, and followed for 1 year, found that VSL\#3 was effective in the primary prevention of pouchitis as only $10 \%$ of patients on VSL\#3 developed acute 
pouchitis compared with $40 \%$ on placebo. ${ }^{89}$ Other studies evaluating the efficacy of Lactobacillus, Bifidobacterium and Clostridium butyricum in the primary prevention of acute pouchitis did not show benefit. ${ }^{90} 91$

VSL\#3 was found to be superior to placebo in maintaining remission in patients with acute pouchitis successfully treated with antibiotics. Sustained remission was observed in $85 \%$ of those treated with VSL\#3 compared with $0 \%$ to $6 \%$ of placebo in two RCTs. ${ }^{92} 93$ The administration of VSL\#3 has been associated with a reduction in pro-inflammatory mediators, increase in regulatory $\mathrm{T}$ cells in the enteric mucosa, ${ }^{94}$ improved barrier function and an increase in intestinal bacterial diversity. ${ }^{95}$

When considering the use of probiotics in IBD, keep in mind that one cannot extrapolate results with one strain or species to another; regrettably, available data involve diverse species and strains and studies are often of low quality precluding generalisable conclusions. ${ }^{96}$ Since IBD disease location, severity and the microbiome can vary significantly between individual patients, it should come as no surprise that responses to probiotics should also vary. Furthermore, many studies have not controlled for confounding factors such as diet and concomitant medications, which can alter the microbial composition of the gut. ${ }^{9798}$

\section{CONCLUSIONS}

An improved understanding of the microbiota in IBD and of its interactions with the intestinal immune system together with high-quality clinical trials are needed to provide generalisable guidelines for the use of antibiotics and probiotics in these disease. Long-term tolerability of antibiotic treatment may be poor due to the appearance of systemic side effects and concern for the development of bacterial resistance. Currently, the use of antibiotics and probiotics should be individualised to the specific patient with IBD based on their diagnosis, location and type of disease.

Contributors BA has contributed to the manuscript by reviewing studies and creating the content of this manuscript. EMMQ has also equally contributed to the manuscript by reviewing studies and creating the content of this manuscript.

Funding The authors have not declared a specific grant for this research from any funding agency in the public, commercial or not-for-profit sectors.

Competing interests None declared.

Patient consent for publication Not required.

Provenance and peer review Commissioned; externally peer reviewed.

ORCID iD

Bincy Abraham http://orcid.org/0000-0003-0308-1224

\section{REFERENCES}

1 Lewis JD, Chen EZ, Baldassano RN, et al. Inflammation, antibiotics, and diet as environmental stressors of the gut microbiome in pediatric Crohn's disease. Cell Host Microbe 2015;18:489-500.
2 Nguyen GC. Tip of the iceberg? The emergence of antibioticresistant organisms in the IBD population. Gut Microbes 2012;3:434-6.

3 Leung W, Malhi G, Willey BM, et al. Prevalence and predictors of MRSA, ESBL, and VRE colonization in the ambulatory IBD population. J Crohns Colitis 2012;6:743-9.

4 Pérez-Cobas AE, Gosalbes MJ, Friedrichs A, et al. Gut microbiota disturbance during antibiotic therapy: a multi-omic approach. Gut 2013;62:1591-601.

5 Khan KJ, Ullman TA, Ford AC, et al. Antibiotic therapy in inflammatory bowel disease: a systematic review and metaanalysis. Am J Gastroenterol 2011;106:661-73.

6 Ledder O, Turner D. Antibiotics in IBD: still a role in the biological era? Inflamm Bowel Dis 2018;24:1676-88.

7 Scarpignato C, Pelosini I, Rifaximin PI. Rifaximin, a poorly absorbed antibiotic: pharmacology and clinical potential. Chemotherapy 2005;51(Suppl 1):36-66.

8 Maccaferri S, Vitali B, Klinder A, et al. Rifaximin modulates the colonic microbiota of patients with Crohn's disease: an in vitro approach using a continuous culture colonic model system. J Antimicrob Chemother 2010;65:2556-65.

9 Cheng J, Shah YM, Ma X, et al. Therapeutic role of rifaximin in inflammatory bowel disease: Clinical implication of human pregnane X receptor activation.J Pharmacol Exp Ther 2010;335:32-41.

10 Prantera C, Lochs H, Campieri M, et al. Antibiotic treatment of Crohn's disease: results of a multicentre, double blind, randomized, placebo-controlled trial with rifaximin. Aliment Pharmacol Ther 2006;23:1117-25.

11 Prantera C, Lochs H, Giochetti P, et al. Rifaximin-EIR (extended intestinal release) $400 \mathrm{mg}$ tablets in the treatment of moderately active Crohn's disease: results of the international multicentre, randomised, double-blind, placebo-controlled trial RETIC-03. Gut 2010;59(Suppl 3).

12 Arnold GL, Beaves MR, Pryjdun VO, et al. Preliminary study of ciprofloxacin in active Crohn's disease. Inflamm Bowel Dis 2002;8:10-15.

13 Steinhart AH, Feagan BG, Wong CJ, et al. Combined budesonide and antibiotic therapy for active Crohn's disease: a randomized controlled trial. Gastroenterology 2002;123:33-40.

14 Ambrose NS, Allan RN, Keighley MR, et al. Antibiotic therapy for treatment in relapse of intestinal Crohn's disease. A prospective randomized study. Dis Colon Rectum 1985;28:81-5.

15 Prantera C, Zannoni F, Scribano ML, et al. An antibiotic regimen for the treatment of active Crohn's disease: a randomized, controlled clinical trial of metronidazole plus ciprofloxacin. Am J Gastroenterol 1996;91:328-32.

16 Sutherland L, Singleton J, Sessions J, et al. Double blind, placebo controlled trial of metronidazole in Crohn's disease. Gut 1991;32:1071-5.

17 Ursing B, Alm T, Bárány F, et al. A comparative study of metronidazole and sulfasalazine for active Crohn's disease: the cooperative Crohn's disease study in Sweden. II. Result. Gastroenterol 1982;83:550-62.

18 Prantera C, Kohn A, Mangiarotti R, et al. Antimycobacterial therapy in Crohn's disease: results of a controlled, double-blind trial with a multiple antibiotic regimen. Am J Gastroenterol 1994;89:513-8.

19 Goodgame RW, Kimball K, Akram S, et al. Randomized controlled trial of clarithromycin and ethambutol in the treatment of Crohn's disease. Aliment Pharmacol Ther 2001;15:1861-6.

20 Selby W, Pavli P, Crotty B, et al. Two-year combination antibiotic therapy with clarithromycin, rifabutin, and clofazimine for Crohn's disease. Gastroenterology 2007;132:2313-9.

21 Aberra FN, Brensinger CM, Bilker WB, et al. Antibiotic use and the risk of flare of inflammatory bowel disease. Clin Gastroenterol Hepatol 2005;3:459-65. 
22 Afdhal NH, Long A, Lennon J, et al. Controlled trial of antimycobacterial therapy in Crohn's disease. Clofazimine versus placebo. Dig Dis Sci 1991;36:449-53.

23 Borgaonkar MR, MacIntosh DG, Fardy JM. A meta-analysis of antimycobacterial therapy for Crohn's disease. Am J Gastroenterol 2000;95:725-9.

24 Bernstein LH, Frank MS, Brandt LJ, et al. Healing of perineal Crohn's disease with metronidazole. Gastroenterology 1980;79:357-65.

25 Brandt LJ, Bernstein LH, Boley SJ, et al. Metronidazole therapy for perineal Crohn's disease: a follow-up study. Gastroenterology 1982;83:383-7.

26 Solomon MJ, McLeod RS, O'Connor BI, et al. Combination of ciprofloxacin and metronidazole in severe perianal Crohn's disease. Can J Gastroenterol 1993;7:571-3.

27 Maeda Y, Ng SC, Durdey P, et al. Randomized clinical trial of metronidazole ointment versus placebo in perianal Crohn's disease. Br J Surg 2010;97:1340-7.

28 West RL, Woude CJ, Hansen BE, et al. Clinical and endosonographic effect of ciprofloxacin on the treatment of perianal fistulae in Crohn's disease with infliximab: a doubleblind placebo-controlled study. Aliment Pharmacol Ther 2004;20:1329-36.

29 Thia KT, Mahadevan U, Feagan BG, et al. Ciprofloxacin or metronidazole for the treatment of perianal fistulas in patients with Crohn's disease: a randomized, double-blind, placebo-controlled pilot study. Inflammatory Bowel Diseases $2009 ; 15: 17-24$.

30 Su JW, Ma JJ, Zhang HJ, et al. Use of antibiotics in patients with Crohn's disease: a systematic review and meta-analysis. $J$ Dig Dis 2015;16:58-66.

31 Rutgeerts P, Hiele M, Geboes K, et al. Controlled trial of metronidazole treatment for prevention of Crohn's recurrence after ileal resection. Gastroenterology 1995;108:1617-21.

32 Rutgeerts P, van Assche G, Vermeire S, et al. Ornidazole for prophylaxis of postoperative Crohn's disease recurrence: A randomized, double-blind, placebo-controlled trial. Gastroenterology 2005;128:856-61.

33 Doherty GA, Bennett GC, Cheifetz AS, et al. Meta-analysis: targeting the intestinal microbiota in prophylaxis for post-operative Crohn's disease. Aliment Pharmacol Ther 2010;31:802-9.

34 Campieri M, Rizzello F, Venturi A, et al. Combination of antibiotic and probiotic treatment is efficacious in prophylaxis of post-operative recurrence of Crohn's disease: a randomized controlled study vs mesalamine. Gastroenterology 2000;118.

35 Herfarth HH, Katz JA, Hanauer SB, et al. Ciprofloxacin for the prevention of postoperative recurrence in patients with Crohn's disease: a randomized, double-blind, placebocontrolled pilot study. Inflamm Bowel Dis 2013;19:1073-9.

36 Rutgeerts P, Geboes K, Vantrappen G, et al. Rifabutin and ethambutol do not help recurrent Crohn's disease in the neoterminal ileum. J Clin Gastroenterol 1992;15:24-8.

37 Rahimi R, Nikfar S, Rezaie A, et al. A meta-analysis of antibiotic therapy for active ulcerative colitis. Dig Dis Sci 2007;52:2920-5.

38 Mantzaris GJ, Archavlis E, Christoforidis P, et al. A prospective randomized controlled trial of oral ciprofloxacin in acute ulcerative colitis. Am J Gastroenterol 1997;92:454-6.

39 Mantzaris GJ, Petraki K, Archavlis E, et al. A prospective randomized controlled trial of intravenous ciprofloxacin as an adjunct to corticosteroids in acute, severe ulcerative colitis. Scand J Gastroenterol 2001;36:971-4.

40 Petersen AM, Mirsepasi H, Halkjær SI, et al. Ciprofloxacin and probiotic Escherichia coli Nissle add-on treatment in active ulcerative colitis: a double-blind randomized placebo controlled clinical trial. J Crohns Colitis 2014;8:1498-505.

41 Turunen UM, Färkkilä MA, Hakala K, et al. Long-term treatment of ulcerative colitis with ciprofloxacin: a prospective, double-blind, placebo-controlled study. Gastroenterology 1998;115:1072-8.

42 Dickinson RJ, O'Connor HJ, Pinder I, et al. Double blind controlled trial of oral vancomycin as adjunctive treatment in acute exacerbations of idiopathic colitis. Gut 1985;26:1380-4.

43 Turner D, Levine A, Kolho K-L, et al. Combination of oral antibiotics may be effective in severe pediatric ulcerative colitis: a preliminary report. J Crohns Colitis 2014;8:1464-70.

44 Burke DA, Axon AT, Clayden SA, et al. The efficacy of tobramycin in the treatment of ulcerative colitis. Aliment Pharmacol Ther 1990;4:123-9.

45 Ohkusa T, Nomura T, Terai T, et al. Effectiveness of antibiotic combination therapy in patients with active ulcerative colitis: a randomized, controlled pilot trial with long-term follow-up. Scand J Gastroenterol 2005;40:1334-42.

46 Ohkusa T, Kato K, Terao S, et al. Newly developed antibiotic combination therapy for ulcerative colitis: a double-blind placebo-controlled multicenter trial. Am J Gastroenterol 2010;105:1820-9.

47 Gionchetti P, Rizzello F, Ferrieri A, et al. Rifaximin in patients with moderate or severe ulcerative colitis refractory to steroidtreatment: a double-blind, placebo-controlled trial. Dig Dis Sci 1999;44:1220-1.

48 Brigidi P, Swennen E, Rizzello F, et al. Effects of rifaximin administration on the intestinal microbiota in patients with ulcerative colitis. J Chemother 2002;14:290-5.

49 Lobo AJ, Burke DA, Sobala GM, et al. Oral tobramycin in ulcerative colitis: effect on maintenance of remission. Aliment Pharmacol Ther 1993;7:155-8.

50 Sandborn WJ, McLeod R, Jewell DP. Medical therapy for induction and maintenance of remission in pouchitis: a systematic review. Inflamm Bowel Dis 1999;5:33-9.

51 Shen B, Achkar JP, Lashner BA, et al. A randomized clinical trial of ciprofloxacin and metronidazole to treat acute pouchitis. Inflamm Bowel Dis 2001;7:301-5.

52 Gionchetti P, Rizzello F, Venturi A, et al. Antibiotic combination therapy in patients with chronic, treatmentresistant pouchitis. Aliment Pharmacol Ther 1999;13:713-8.

53 Mimura T, Rizzello F, Helwig U, et al. Four-week open-label trial of metronidazole and ciprofloxacin for the treatment of recurrent or refractory pouchitis. Aliment Pharmacol Ther 2002;16:909-17.

54 Shen B, Remzi FH, Lopez AR, et al. Rifaximin for maintenance therapy in antibiotic-dependent pouchitis. BMC Gastroenterol $2008 ; 8$.

55 Madden MV, McIntyre AS, Nicholls RJ. Double-blind crossover trial of metronidazole versus placebo in chronic unremitting pouchitis. Dig Dis Sci 1994;39:1193-6.

56 Howarth GS, Wang H. Role of endogenous microbiota, probiotics and their biological products in human health. Nutrients 2013;5:58-81.

57 Hill C, Guarner F, Reid G, et al. Expert consensus document. The International Scientific Association for Probiotics and Prebiotics consensus statement on the scope and appropriate use of the term probiotic. Nat Rev Gastroenterol Hepatol 2014;11:506-14.

58 Food and Agriculture Organization of the United Nations and World Health Organization. Health and nutritional properties of probiotics in food including powder milk with live lactic acid bacteria, 2001. Available: http://www.who.int/foodsafety/ publications/fs_management/en/probiotics.pdf

59 Abraham BP, Quigley EMM. Probiotics in inflammatory bowel disease. Gastroenterol Clin North Am 2017;46:769-82.

60 Sartor RB. Therapeutic manipulation of the enteric microflora in inflammatory bowel diseases: antibiotics, probiotics, and prebiotics. Gastroenterology 2004;126:1620-33.

61 Gionchetti P, Rizzello F, Lammers K-M, et al. Antibiotics and probiotics in treatment of inflammatory bowel disease. World J Gastroenterol 2006;12:3306-13. 
62 Didari T, Solki S, Mozaffari S, et al. A systematic review of the safety of probiotics. Expert Opin Drug Saf 2014;13:227-39.

63 Doron S, Snydman DR. Risk and safety of probiotics. Clin Infect Dis 2015;60(Suppl 2):S129-S134.

64 Gupta P, Andrew H, Kirschner BS, et al. Is Lactobacillus GG helpful in children with Crohn's disease? Results of a preliminary, open-label study. J Pediatr Gastroenterol Nutr 2000;31:453-7.

65 Fujimori S, Tatsuguchi A, Gudis K, et al. High dose probiotic and prebiotic cotherapy for remission induction of active Crohn's disease. J Gastroenterol Hepatol 2007;22:1199-204.

66 Schultz M, Timmer A, Herfarth HH, et al. Lactobacillus GG in inducing and maintaining remission of Crohn's disease. BMC Gastroenterol 2004;4.

67 Bousvaros A, Guandalini S, Baldassano RN, et al. A randomized, double-blind trial of Lactobacillus GG versus placebo in addition to standard maintenance therapy for children with Crohn's disease. Inflamm Bowel Dis 2005;11:833-9.

68 Bourreille A, Cadiot G, Le Dreau G, et al. Saccharomyces boulardii does not prevent relapse of Crohn's disease. Clin Gastroenterol Hepatol 2013;11:982-7.

69 Marteau P, Lémann M, Seksik P, et al. Ineffectiveness of Lactobacillus johnsonii LA1 for prophylaxis of postoperative recurrence in Crohn's disease: a randomised, double blind, placebo controlled GETAID trial. Gut 2006;55:842-7.

70 Van Gossum A, Dewit O, Louis E, et al. Multicenter randomized-controlled clinical trial of probiotics (Lactobacillus johnsonii, LA1) on early endoscopic recurrence of Crohn's disease after lleo-caecal resection. Inflamm Bowel Dis 2007;13:135-42.

71 Malchow HA. Crohn's disease and Escherichia coli. A new approach in therapy to maintain remission of colonic Crohn's disease? J Clin Gastroenterol 1997;25:653-8.

72 Fedorak RN, Feagan BG, Hotte N, et al. The probiotic VSL\#3 has anti-inflammatory effects and could reduce endoscopic recurrence after surgery for Crohn's disease. Clin Gastroenterol Hepatol 2015;13:928-35.

73 Mallon P, McKay D, Kirk S, et al. Probiotics for induction of remission in ulcerative colitis. Cochrane Database Syst Rev 2007;4.

74 Tursi A, Brandimarte G, Papa A, et al. Treatment of relapsing mild-to-moderate ulcerative colitis with the probiotic VSL\#3 as adjunctive to a standard pharmaceutical treatment: a double-blind, randomized, placebo-controlled study. Am J Gastroenterol 2010;105:2218-27.

75 Sood A, Midha V, Makharia GK, et al. The probiotic preparation, VSL\#3 induces remission in patients with mildto-moderately active ulcerative colitis. Clin Gastroenterol Hepatol 2009;7:1202-9.

76 Miele E, Pascarella F, Giannetti E, et al. Effect of a probiotic preparation (VSL\#3) on induction and maintenance of remission in children with ulcerative colitis. Am J Gastroenterol 2009;104:437-43.

77 Kato K, Mizuno S, Umesaki Y, et al. Randomized placebocontrolled trial assessing the effect of bifidobacteria-fermented milk on active ulcerative colitis. Aliment Pharmacol Ther 2004;20:1133-41.

78 Matthes H, Krummenerl T, Giensch M, et al. Clinical trial: probiotic treatment of acute distal ulcerative colitis with rectally administered Escherichia coli Nissle 1917 (EcN). BMC Complement Altern Med 2010;10.

79 Oliva S, Di Nardo G, Ferrari F, et al. Randomised clinical trial: the effectiveness of Lactobacillus reuteri ATCC 55730 rectal enema in children with active distal ulcerative colitis. Aliment Pharmacol Ther 2012;35:327-34.
80 Shanahan F, Collins SM. Pharmabiotic manipulation of the microbiota in gastrointestinal disorders, from rationale to reality. Gastroenterol Clin North Am 2010;39:721-6.

81 Kruis W, Schütz E, Fric P, et al. Double-blind comparison of an oral Escherichia coli preparation and mesalazine in maintaining remission of ulcerative colitis. Aliment Pharmacol Ther 1997;11:853-8.

82 Rembacken BJ, Snelling AM, Hawkey PM, et al. Nonpathogenic Escherichia coli versus mesalazine for the treatment of ulcerative colitis: a randomised trial. Lancet 1999;354:6359.

83 Kruis W, Fric P, Pokrotnieks J, et al. Maintaining remission of ulcerative colitis with the probiotic Escherichia coli Nissle 1917 is as effective as with standard mesalazine. Gut 2004;53:161723.

84 Zocco MA, dal Verme LZ, Cremonini F, et al. Efficacy of Lactobacillus GG in maintaining remission of ulcerative colitis. Aliment Pharmacol Ther 2006;23:1567-74.

85 Huynh HQ, deBruyn J, Guan L, et al. Probiotic preparation VSL\#3 induces remission in children with mild to moderate acute ulcerative colitis: a pilot study. Inflamm Bowel Dis $2009 ; 15: 760-8$.

86 Guslandi M. Saccharomyces boulardii plus rifaximin in mesalamine-intolerant ulcerative colitis. J Clin Gastroenterol 2010;44.

87 Sandborn WJ. Pouchitis following ileal pouch-anal anastomosis: definition, pathogenesis, and treatment. Gastroenterology 1994;107:1856-60.

88 Kuisma J, Mentula S, Jarvinen H, et al. Effect of Lactobacillus rhamnosus GG on ileal pouch inflammation and microbial flora. Aliment Pharmacol Ther 2003;17:509-15.

89 Gionchetti P, Rizzello F, Helwig U, et al. Prophylaxis of pouchitis onset with probiotic therapy: a double-blind, placebo-controlled trial. Gastroenterology 2003;124:1202-9.

90 Tomasz B, Zoran S, Jarosław W, et al. Long-term use of probiotics Lactobacillus and Bifidobacterium has a prophylactic effect on the occurrence and severity of pouchitis: a randomized prospective study. Biomed Res Int 2014;2014:1-4.

91 Yasueda A, Mizushima T, Nezu R, et al. The effect of Clostridium butyricum MIYAIRI on the prevention of pouchitis and alteration of the microbiota profile in patients with ulcerative colitis. Surg Today 2016;46:939-49.

92 Gionchetti P, Rizzello F, Venturi A, et al. Oral bacteriotherapy as maintenance treatment in patients with chronic pouchitis: a double-blind, placebo-controlled trial. Gastroenterology 2000;119:305-9.

93 Mimura T, Rizzello F, Helwig U, et al. Once daily high dose probiotic therapy (VSL\#3) for maintaining remission in recurrent or refractory pouchitis. Gut 2004;53:108-14.

94 Pronio A, Montesani C, Butteroni C, et al. Probiotic administration in patients with ileal pouch-anal anastomosis for ulcerative colitis is associated with expansion of mucosal regulatory cells. Inflamm Bowel Dis 2008;14:662-8.

95 Landy J, Hart A. Commentary: the effects of probiotics on barrier function and mucosal pouch microbiota during maintenance treatment for severe pouchitis in patients with ulcerative colitis. Aliment Pharmacol Ther 2013;38:1405-6.

96 Dong J, Teng G, Wei T, et al. Methodological quality assessment of meta-analyses and systematic reviews of probiotics in inflammatory bowel disease and pouchitis. PLOS One 2016;11:e0168785.

97 Francino MP. Antibiotics and the human gut microbiome: dysbioses and accumulation of resistances. Front Microbiol 2015;6.

98 David LA, Maurice CF, Carmody RN, et al. Diet rapidly and reproducibly alters the human gut microbiome. Nature 2014;505:559-63. 